\title{
Current Trends in Remote and Virtual Lab Engineering. Where are we in 2013?
}

http://dx.doi.org/10.3991/ijoe.v9i6.2898

\author{
S. Seiler \\ it:matters, Bochum, Germany
}

\begin{abstract}
This article is introducing latest developments and trends in remote and virtual technologies and their application in engineering education. The author gives an overview about the potential of utilizing remote engineering in engineering research, education and professional training, focusing on different kinds of technological characteristics. In conclusion, possible ways of further advancement are presented.
\end{abstract}

Index Terms - remote engineering, remote lab, virtual lab

\section{INTRODUCTION}

Nowadays the engineering industry is characterized by rapidly occurring innovations and continuous advancement of existing technologies. Therefore, it is quite a challenge for research institutions to keep up with the high pace of technological advancements in industry by being up to date with facilities, educational concepts and curricula $[1,2]$. According to Carew and Cooper, engineering is "a field where innovations in technology mean that $/ . . . /$ connection between engineering curriculum and the technology used in industry need[s] constant attention."[3].

\section{A. Issues in engineering education}

Where the utilization of modern technology is finding its way into our digital society, this evolution is accompanied by a lack of adolescent interest in taking part in scientific and technological development, as expressed in [4],[5] and [6]. The engineering qualification has to become more attractive to young people and feasible to fulltime employees in order to stay at a high level in product development and to inspire potential engineering students. Engineering research, education and professional training is shaped by the utilization of practical hands-on experimentation facilities (called "labs" from here on), much more than in any other scientific discipline. A particular lab (e.g. an "industrial robot arm" or a "production line") might be too expensive to be purchased by a single research and engineering institution or too large to be placed in a small research facility.

\section{B. Benefits of lab sharing}

This raises the idea of sharing labs between different institutions as explained in [7]. Cooper and Ferreira note about remote experimentation, "it appears to offer a simple solution to problems of distance, collaboration, expensive equipment, and limited availability." [8]. Gravier et al. further report other expectations in lab sharing, which are non-monetary and apply quite well for research applications, like "security", "observability", "dangerous- ness", "accessibility" and "availability" [7]. Taking hazardous research experiments into account, these could be achieved more securely by utilizing remote lab technology. The general idea of equipment sharing without enterprise or institutional borders supports the research scheme of Factories of the Future as it enhances industrial research through mediating access to expensive equipment for technology-driven SMEs or industry. One of such application can be, for instance, a research institution certified tests for industry with remote observation. In the preface to [9], Zvacek summarizes the advantages of remote labs. According to her, "the benefits are likely to include increased $/ \ldots /$ access to equipment, greater flexibility in lab scheduling, a wider range of possible assignments of activities, and enhanced opportunities for collaboration /.../.". The authors' goal in [10] is "to use modern technology to provide students with enough learning opportunities to conduct science experiments that are essential to science education". M. R. Kadhum and S. Kadry notice the "lack of the modern laboratory in scientific institutes"[11] as a reason for the need to develop remote lab infrastructure.

Henke, Ostendorff and Wuttke report about the remote lab's advantages: "it gives the student the possibility to work on real world systems without the need to stand in line at a lab or the need to take care of opening hours"[12]. Facer and Sandford argue that the educational development should "move beyond pedagogy to curriculum; beyond the school to the community, home and workplace"[13].

In a guest editorial [14], Auer and Gravier introduce the many facets of remote labs. Authors in [15-17] discuss the general role of labs in engineering science in more detail.

Summarizing these statements, remote labs offer various advantages over conventional labs, far beyond budget issues for both research and education.

\section{LAB SHARING INITIATIVES}

There have been several attempts in the last decade to deal with the issues mentioned here. The goals of the iLabs project at Massachusetts Institute of Technology in USA, were to develop a suite of software tools to facilitate online complex laboratory experiments, i.e., "minimize development and management effort for users and providers of remote labs, provide a common set of services and development tools, scale to large numbers of users worldwide, allow multiple universities with diverse network infrastructures to share access" [13], [18-20]. Au- 
thors in [21], have compared three web services based architectures of remote laboratories, DIBE ISILab (Internet Shared Instrumentation Laboratory), HPI DCL (Distributed Control Laboratory) and MIT iLab, according to user interactions and interoperability between remote labs. All of these architectures collect in a web service interface all the functionalities exposed by the lab, and use work sessions to structure measurements and store data sent or received from the instruments. The authors also stated that "structuring remote laboratory functions as a set of services has the major advantage of allowing the sharing of the physical experimental setup, while leaving the possibility of customizing the client application interface".

\section{DIFFERENT APPROACHES IN LAB SHARING}

Where most approaches [22-26] focus on a single lab integration, the authors in [27-28] suggest a "Service Oriented Laboratory Architecture" approach.

From the interoperability perspective, the authors have tested and proved the possibility of sharing remote experiments between different institutions [29], as did the consortium of the author of this article [30-33].

Currently, there is very little evidence for significant sharing of distance lab hardware between different institutions [34]. Different facilities have their own technological approaches, so sharing is very complicated since external software components and data sources cannot be integrated into existing platforms without major expense.

The requirements in technical knowhow, programming skills and time are too high for most teaching staff. Furthermore, there are no common documentation sets, software platforms or reusable libraries to reduce the workload for a remote and virtual lab provider. The complexity of the common approaches delays the evolution of distance lab solutions and hinders a thematically wider range of potential lab providers and users from participating in distance lab networks.

\section{A. Current limitation in remote lab sharing}

To solve the problem of providing practical skills to students despite the lack of equipment and funds in educational institutions, technology enhanced learning based on the sharing of equipment between institutions is suggested for wide-scale implementation across countries [7], [35]. Advances in internet-based technologies allow institutions, SMEs and private individuals to access the equipment of other organizations. However, the main problem today is that there are no standards or recommendations regarding the requirements for such equipment (electrical signals, communicational protocols and compatibility of software). There are merely some suggestions ([35-37]) but no DIN, ISO, or IEEE standards.

Changing the view to subparts and subsystems, there are some existing (semantic) descriptions for various science areas, such as sensor descriptions.

For instance, in 2009 Compton et al. analyzed in [38] 12 different sensor ontologies. While some of them (like Avancha [39] and CESN [40]) are merely descriptions of sensors, other like OntoSensor [41] are also capable of describing 'components', or like OOSTethys 'processes' in addition. Their conclusion gives the statement that a "combination of OntoSensor and the CSIRO ontology represents the current limit of expressive capability for semantic sensors" [38], but none of them is able to deal with the whole context of sensor descriptions.

For user interfaces it is almost the same situation. Various descriptive approaches exist and are discussed in the Model-Based User Interfaces Incubator Group at W3C. These approaches can be separated into industrial (Collage, Flex, Open Laszlo and XAML for instance) and research driven (CAMELEON Reference Framework, MARIA and UsiXML for instance) ones (compare: [42]).

Universities across the world are developing different types of remote labs for their own interests [7],[43-44]. However, there is very little evidence at the present time that such local labs are used by other institutions in order to provide educational support for a wider range of students on a regular basis.

The common web browser is widely used to access remote and virtual laboratories [45-46]. Authors in [47] have introduced the concept of "experiment as a service" and developed a service-based software infrastructure for remote laboratories, called DCL (Distributed Control $\mathrm{Lab}$ ). Examples of integrated experiments available on DCL are "Higher Striker" (a real-time control experiment), a programmable logic controller and embedded real-time control applications. This work has been undertaken under the Vet-Trend project [48], with the main objective to build an open infrastructure for conducting robotics and real-time control experiments from the Web. Unfortunately, this concept has not become widespread so far since there is no established standard and the software components used in DCL are not publicly available.

Authors in [49], under a project called VISIR (Virtual Systems in Reality), developed software to allow users in various universities and other organizations to set up online lab workbenches for electrical experiments. The software is used by two universities and students can perform simultaneous experiments on online workbenches.

Several other virtual and remote laboratories have been developed for a variety of disciplines [21],[50-51]. However, the diverse proprietary interfaces, software components and implementations for each experiment are a problem for learners and teachers (no common user interfaces and APIs are used). Therefore, it is hard to integrate new remote labs or create virtual labs. Due to incompatible software implementations it is a hard task to integrate external labs into an existing lab platform. That complicates the sharing of labs between different organizations and universities.

Another major problem that slows down the evolution and distribution of distance labs is that very few qualified staff members are capable of providing lab equipment on the internet, not to mention that it is even more complicated to completely virtualise given hardware components. A strong indicator for this is that most of the distributed labs are engineering related; teachers from other disciplines who lack an affinity to programming are less likely to provide their labs on the internet since they lack the technical knowledge and support to do so. Most of the existing Labs are tailored lab-specific experiments (for instance: [52-55] and use diverse proprietary interfaces and implementations but there is no common user interface and no common APIs, nor a common description of them. Despite that, many labs share similar requirements; new experiments require new developments, logic, connectors and user interfaces. In other words, technologies used in 
current labs mainly lack reusability and interoperability, for instance they are not generic enough to be reused when designing and integrating new Labs.

\section{CONCLUSION}

As a possible solution for the mentioned issues, there is an urgent need for standardization in this field. According to authors in [34], [56-58] a more generalized approach is necessary to establish a wider use of remote labs in research and education. One important step in this direction is the development of a common language for the lab integration [59] as well as a comprehensive soft- and hardware toolbox including documentation for automated plug and play distribution of remote and virtual labs gives an overview of different types of online accessible labs. In addition, there needs to be an adequate implementation of technology-enhanced learning in the practical orientated parts of engineering education by embedding these approaches into learning concepts.

One starting point to conquer these problems is to offer web based technologies for remote access to equipment and eLearning in blended learning education with the assistance of internet-accessible labs and experiments.

Author of this article is looking forward for new results, that should came out of the current project "Global Online Science Labs for Inquiry Learning at School" funded by the EU in their Seventh Framework Programme ${ }^{1}$.

\section{ACKNOWLEDGMENT}

The author would like to thank Raivo Sell for his contribution to the overall work and for being supervisor of the authors' doctoral thesis.

This article is supported by EU Life Long Learning program projects "Virtual Academy Platform for Vocational Schools (VAPVoS)" (DE-11-LLP-LdV-TOI147410) and "Learning Situations in Embedded System StudyLab (Netlab)" (2011-0019-LEO05-TOI-01).

\section{REFERENCES}

[1] A. Al-Ashaaba, M. Floresb, A. Doultsinoua, and A. Magyara, “A balanced scorecard for measuring the impact of industryuniversity collaboration," Production Planning and Control: The Management of Operations, vol. 22, 2011.

[2] R. Habash, "Mechatronics learning studio: From "play and learn" to industry-inspired green energy applications," IEEE Transactions on Education, vol. 54, pp. 667-674, 2011. http://dx.doi.org/10.1109/TE.2011.2107555

[3] A. Carew and P. Cooper, "Engineering curriculum review: processes, frameworks and tools," in Proceedings of the Annual SEFI Conference, 2008.

[4] F. S. Becker, "Why don't young people want to become engineers? rational reasons for disappointing decisions," European Journal of Engineering Education, vol. 35, pp. 349-366, 2010. [Online]. Available: http://www.tandfonline.com/doi/abs/10.1080/ 03043797.2010.489941g

[5] L. L. Bucciarellia, "Ethics and engineering education," European Journal of Engineering Education, vol. 33, pp. 141-149, 2008. [Online]. Available: http://www.tandfonline.com/doi/abs/10.1080/ $03043790801979856 \mathrm{~g}$

[6] K. J. B. Andersona, S. S. Courterb, T. McGlameryb, T. M. Nathans-Kellyb, and C. G. Nicometob, "Understanding engineering work and identity: a cross-case analysis of engineers within six firms," Engineering Studies, vol. 2, pp. 153-174, 2010. [Online].

\footnotetext{
${ }^{1}$ The project website can be found at http://www.go-lab-project.eu/.
}

Available: http://www.tandfonline.com/doi/abs/10.1080/030437 90801979856g

[7] C. Gravier, J. Fayolle, B. Bayard, M. Ates, and J. Lardon, "State of the art about remote laboratories paradigms - foundations of ongoing mutations," International Journal of Online Engineering, vol. 4, 2008

[8] M. Cooper and J. M. Ferreira, "Remote laboratories extending access to science and engineering curricular," IEEE Transactions On Learning Technologies, vol. 2, no. 4, pp. 342-353, OctoberDecember 2009. http://dx.doi.org/10.1109/TLT.2009.43

[9] J. Zub'ia and G. Alves, Using Remote Labs in Education: Two Little Ducks in Remote Experimentation. Universidad de Deusto, 2012. [Online]. Available: http://books.google.de/books?id=PQ sXw6q5arIC

[10] Y. hui Vanessa Chiang, A. Karimi, and P. Kim, "A remotely operated science experiment (rose) framework to boost a sense of sharing laboratory resources through a technology-mediated interface," in Proceedings of Society for Information Technology \& Teacher Education International Conference 2012, P. Resta, Ed. Austin, Texas, USA: AACE, March 2012, pp. 249-252. [Online]. Available: http://www.editlib.org/p/39570

[11] M. R. Kadhum and S. Kadry, "New design of robotics remote lab," International Journal of Advanced Computer Sciences and Applications, vol. 3, pp. 79-85, 2012.

[12] K. Henke, S. Ostendorff, and H.-D. Wuttke, A Flexible and Scalable Infrastructure for Remote Laboratories - Robustness in Remote Engineering Laboratories. Bremen, Berlin, Heidelberg: The Impact of Virtual, Remote and Real Logistics Labs - ImViReLL2012 in: CCIS 282, Springer Verlag, 022012.

[13] K. Facer and R. Sandford, "The next 25 years?: future scenarios and future directions for education and technology," Journal of Computer Assisted Learning, vol. 26, pp. 74-93, 2010. http://dx.doi.org/10.1111/j.1365-2729.2009.00337.x

[14] M. E. Auer and C. Gravier, "Guest editorial: The many facets of remote laboratories in online engineering education," IEEE Transactions On Learning Technologies, vol. 2, no. 4, pp. 260-262, October-December 2009. http://dx.doi.org/10.1109/TLT.2009.53

[15] L. D. Feisel and A. J. Rosa, "The role of the laboratory in undergraduate engineering education," Journal of Engineering Education, vol. 94, pp. 121-130, 2005. http://dx.doi.org/10.1002/j.21689830.2005.tb00833.x

[16] S. R. Hiltz and M. Turoff, "Education goes digital: The evolution of online learning and the revolution in higher education," Communications of the ACM, vol. 48, no. 10, pp. 59-64, October 2005. http://dx.doi.org/10.1145/1089107.1089139

[17] A. Hofstein and V. N. Lunetta, "The laboratory in science education: Foundations for the twenty-first century," Science Education, vol. 88, December 2003.

[18] V. Harward, J. del Alamo, S. Lerman, P. Bailey, J. Carpenter, K. DeLong, C. Felknor, J. Hardison, B. Harrison, I. Jabbour, P. Long, T. Mao, L. Naamani, J. Northridge, M. Schulz, D. Talavera, C. Varadharajan, S. Wang, K. Yehia, R. Zbib, and D. Zych, "The ilab shared architecture: A web services infrastructure to build communities of internet accessible laboratories," Proceedings of the IEEE, vol. 96, no. 6, pp. 931 -950, june 2008. http://dx.doi.org/10.1109/JPROC.2008.921607

[19] A. Jiwaji, K. J. Hardison, K. P. Ayodele, S. Stevens, M. A, V. J. Harward, J. A. del Alamo, B. Harrison, and S. Gikandi, "Collaborative development of remote electronics laboratories: The elvis ilab," ASEE Annual Conference \& Exposition, June 2009.

[20] B.-A. Deaky, D. Zutin, and P. Bailey, "A detailed view of the first android client application for the ilab shared architecture," in Global Engineering Education Conference (EDUCON), 2012 IEEE, april 2012, pp. $1-6$. http://dx.doi.org/10.1109/EDU CON.2012.6201204

[21] D. Ponta, A. M. Scapolla, and P. Buschiazzo, "Survey of remote laboratories using service oriented architectures," iJOE, vol. 5, 2009.

[22] A. C. Hyder, J. L. Thames, and D. Schaefer, "Enhancing mechanical engineering distance education through it-enabled remote laboratories," ASME Conference Proceedings, vol. 2009, no. 49057, pp. 491-500, 2009. [Online]. Available: http://link.aip.org/link/ abstract/ASMECP/v2009/i49057/p491/s1 
[23] Z. Aydogmus and O. Aydogmus, "A web-based remote access laboratory using scada," Education, IEEE Transactions on, vol. 52, no. 1, pp. $126-132$, February 2009. http://dx.doi.org/10.1109/ TE. 2008.921445

[24] U. Hernandez-Jayo and J. Garcia-Zubia, "Control methodology independent of the experiments to be deployed in remote labs of analog electronic," in Global Engineering Education Conference (EDUCON), 2012 IEEE, april 2012, pp. 1 -6. http://dx.doi.org/10.1109/EDUCON.2012.6201042

[25] D. Gurkan, A. Mickelson, and D. Benhaddou, "Remote laboratories for optical circuits," Education, IEEE Transactions on, vol. 51, no. 1, pp. 53-60, feb. 2008. http://dx.doi.org/10.1109/ TE.2007.900018

[26] B. Pradarelli, L. Latorre, M.-L. Flottes, Y. Bertrand, and P. Nouet, "Remote labs for industrial ic testing," IEEE Transactions on Learning Technologies, vol. 2, pp. 304 - 311, 2009. http://dx.doi.org/10.1109/TLT.2009.46

[27] J. Garcia-Zubia, P. Orduna, D. Lopez-de Ipina, and G. Alves, "Addressing software impact in the design of remote laboratories," Industrial Electronics, IEEE Transactions on, vol. 56, no. 12, pp. 4757 -4767, dec. 2009. http://dx.doi.org/10.1109/TIE.2009. 2026368

[28] S. Jeschke, A. Gramatke, O. Pfeiffer, C. Thomsen, and T. Richter, "Networked virtual and remote laboratories for research collaboration in natural sciences and engineering," in Adaptive Science Technology, 2009. ICAST 2009. 2nd International Conference on, jan. 2009, pp. 73-77.

[29] L. Gomes and S. Bogosyan, "Current trends in remote laboratories," Industrial Electronics, IEEE Transactions on, vol. 56, no. 12, pp. 4744-4756, dec. 2009. http://dx.doi.org/10.1109/TIE.2009. 2033293

[30] S. Seiler and R. Sell, "Comprehensive blended learning concept for teaching micro controller technology utilising homelab kits and remote labs in a virtual web environment," Transactions on Edutainment X, Number 7775, pages: 161-177, ISBN: 978-3-64237918-5, Springer Berlin Heidelberg, Germany, DOI: http://dx.doi.org/10.1007/978-3-642-37919-2 9

[31] S. Seiler, R. Sell, and D. Ptasik, "Embedded system and robotic education in a blended learning environment utilizing remote and virtual labs in the cloud, accompanied by robotic homelab kit," International Journal of Emerging Technologies in Learning (iJET), vol. 7, no. 4,2012.

[32] S. Seiler, R. Sell, D. Ptasik, and M. Boelter, "Holistic web-based virtual micro controller framework for research and education," International Journal of Online Engineering, vol. 8, November 2012.

[33] S. Seiler and R. Sell, "Improvements of multi-disciplinary engineering study by exploiting design-centric approach, supported by remote and virtual labs," International Journal of Engineering Education, vol. 28, p. 759766, December 2012.

[34] S. Seiler, "Laboratory as a service a holistic framework for remote and virtual labs," Ph.D. dissertation, Tallinn University of Technology, October 2012. ISBN 9789949233601 (publication), ISBN 9789949233618 (pdf), ISSN 14064758

[35] A. C. Ammari and J. Ben Hadj Slama, "The development of a remote laboratory for internet based engineering education," Journal of Asynchronous Learning Networks, 2006.

[36] B. Balamuralithara and P. Woods, "Virtual laboratories in engineering education: The simulation lab and remote lab," Computer Applications in Engineering Education, vol. 17, pp. 108-118, 2007. http://dx.doi.org/10.1002/cae.20186

[37] N. E. Cagiltay, E. Aydin, R. Oktem, A. Kara, M. Alexandru, and B. Reiner, "Requirements for remote rf laboratory applications: An educators perspective," IEEE Transactions on Education, vol. $52,2009$.

[38] M. Compton, C. Henson, L. Lefort, H. Neuhaus, and A. Sheth, "A survey of the semantic specification of sensors," in Proceedings of the $8^{\text {th }}$ International Semantic Web Conference (ISWC 2009), 2nd International Workshop on Semantic Sensor Networks, K. Taylor, Ed., 2009.

[39] S. Avancha, C. Patel, and A. Joshi, "Ontology-driven adaptive sensor networks.” in MobiQuitous'04, 2004, pp. 194-202.
[40] C. E. S. Networks, "Cesn ontology," http://www.cesn.org/resour ces/cesn.owl, 2011, online, accessed 25. March 2012.

[41] D. Russomanno, C. Kothari, and O. Thomas, "Building a sensor ontology: A practical approach leveraging iso and ogc models," in The 2005 International Conference on Artificial Intelligence, 2005, pp. 637-643.

J. M. C. Fonseca, J. M. G. Calleros, G. Meixner, F. Patern, J. Pullmann, D. Raggett, D. Schwabe, and J. Vanderdonckt, "ModelBased UI XG Final Report," http://www.w3.org/2005/Incubator/ model-based-ui/XGRmbui-20100504/

[42] R. J. Sepe, M. Chamberland, and N. Short, "Web-based virtual engineering laboratory (ve-lab) for a hybrid electric vehicle starter/alternator," Industry Applications Conference, 1999. ThirtyFourth IAS Annual Meeting. Conference Record of the 1999 IEEE, vol. 4, pp. $2642-2648,1999$.

[43] A. I. El-Osery, J. Burge, A. Saba, M. Jamshidi, M. Fathi, Mohammad-R., and Akbarzadeh-T, "V-lab; - a virtual laboratory for autonomous agents - sla based controllers," IEEE Transactions on Systems, Man and Cybernetics, vol. 32, pp. 791-803, 2002. http://dx.doi.org/10.1109/TSMCB.2002.1049613

[44] V. Padman and N. Memon, "Design of a virtual laboratory for information assurance education and research," in Proceedings of the 2002 IEEE Workshop on Information Assurance and Security, 2002.

[45] T. J. Llus Fbrega, Jordi Massaguer and D. Mrida, "A virtual network laboratory for learning ip networking," in ITiCSE '02 Proceedings of the 7th annual conference on Innovation and technology in computer science education, vol. 34. ACM SIGCSE Bulletin, 2002.

[46] F. F. Peter Troger, Andreas Rasch and R. Wierschke, "Soa meets robots - a service-based software infrastructure for remote laboratories," Proceedings of the 2nd International Workshop on elearning and Virtual and Remote laboratories, 2008.

[47] A. Rasche, F. Feinbube, P. Trger, B. Rabe, and A. Polze, "Predictable interactive control of experiments in a service-based remote laboratory," in Proceedings of the 1st ACM International Conference on Pervasive Technologies, 2008.

[48] I. Gustavsson, J. Zackrisson, K. Nilsson, J. Garcia-Zubia, L. Hkansson, I. Claesson, and T. Lag, "A flexible electronics laboratory with local and remote workbenches in a grid," International Journal of Online Engineering (iJOE), vol. 4, 2008.

[49] P. Buschiazzo, D. Leoncini, R. Zunino, and A. M. Scapolla, "A web-based laboratory for digital signal processing," iJOE, vol. 6, no. S1, pp. 6-11, 2010. [Online]. Available: http://dblp.unitrier.de/db/journals/ijoe/ijoe6.html\#BuschiazzoLZS10

[50] F. Davoli, F. G. Spano, S. Vignola, and S. Zappatore, "Labnet: Towards remote laboratories with unified access," in IEEE Transactions on Instrumentation and Measurement, vol. 5, 2006, pp. 1551-1558. http://dx.doi.org/10.1109/TIM.2006.880919

[51] L. Costas-Prez, D. Lago, J. Faria, and J. J. Rodriguez-Andina, "Optimization of an industrial sensor and data acquisition laboratory through time sharing and remote access," IEEE Transactions on Industrial Electronics, vol. 55, no. 6, pp. 2397-2404, June 2008. http://dx.doi.org/10.1109/TIE.2008.921687

[52] R. Hashemian and T. R. Pearson, "A low-cost server-client methodology for remote laboratory access for hardware design," in 39th ASEE/IEEE Frontiers in Education Conference, 2009.

[53] D. Hercog, B. Gergi, S. Uran, and K. Jezernik, "Dspbased remote control laboratory," IEEE Transactions On Industrial Electronics, vol. 54, no. 6, pp. 3057-3068, December 2007. http://dx.doi.org/10.1109/TIE.2007.907009

[54] N. Lewis, M. Billaud, D. Geoffroy, P. Cazenave, and T. Zimmer, "A distance measurement platform dedicated to electrical engineering," IEEE Transactions On Learning Technologies, vol. 2, no. 4, pp. 312-319, October-December 2009. http://dx.doi.org/10.1109/TLT.2009.45

[55] M. Ngolo, L. Palma, F. Coito, L. Gomes, and A. Costa, "Architecture for remote laboratories based on rest web services," in ELearning in Industrial Electronics, 2009. ICELIE '09. 3rd IEEE International Conference on, nov. 2009, pp. $30-35$.

[56] A. Bagnasco, A. Boccardo, P. Buschiazzo, A. Poggi, and A. M. Scapolla, "A service-oriented educational laboratory for electron- 
ics," IEEE Transactions On Industrial Electronics, vol. 56, no. 12, December 2009. http://dx.doi.org/10.1109/TIE.2008.2002729

[57] S. Odeh, "Building reusable remote labs with adaptable client userinterfaces," Journal of Computer Science and Technology, vol. 25, no. 4, pp. 999-1015, 2010

[58] Seiler, S.; Ptasik, D.; Sell, R., "Lab Description Language - A framework approach for describing and mediating remote and virtual labs," Mechatronics (MECATRONICS), 2012 9th FranceJapan \& 7th Europe-Asia Congress on and Research and Education in Mechatronics (REM), 2012 13th Int'l Workshop on, vol., no., pp.194,198, 21-23 Nov. 2012 http://dx.doi.org/10.1109/ MECATRONICS.2012.6451008, http://ieeexplore.ieee.org/stamp/ stamp.jsp?tp $=$ \&arnumber $=6451008 \&$ isnumber $=6450975$

\section{AUTHOR}

S. Seiler received his engineering degree in computer sciences from Bochum University of Applied Sciences, Bochum, Germany in 2007, and the M.Sc. and Ph.D. degrees in Mechatronics/Mechanical Engineering from Tallinn University of Technology in 2009 and 2012, respectively. In 2007 he joined the Department of Electrical Engineering and Computer Sciences, Bochum University of Applied Sciences as a Researcher and in 2012 he became a contract teacher. His current research interests are technology-enhanced learning and the application of modern Internet technologies in ubiquitous computing.

Manuscript received 09 June 2013. Published as re-submitted by the author 22 October 2013 .. 